\title{
СИСТЕМА РАЗМЕТКИ ЗВУЧАЩЕЙ РЕЧИ ДЛЯ СРАВНИТЕЛЬНОГО АНАЛИЗА ПРОИЗНОШЕНИЯ В РАЗЛИЧНЫХ ДИАЛЕКТАХ
}

\author{
(c) 2020 Ю. И. Бутенко ${ }^{\bowtie}$, Ю. В. Строганов, В. И. Шевченко, Н. В. Славнов, А. В. Квасников
}

\author{
Московский государственный технический университет им. Н. Э. Баумана \\ 2-я Бауманская ул., 5, стр. 1, 105005 Москва, Российская Федерация
}

\begin{abstract}
Аннотация. Статья посвящена разработке системы разметки для сравнительного анализа произношения в различных диалектах русского языка. Подчеркнуто, что в настоящее время широко используется голосовой ввод с использованием голосовых помощников, чьей основной проблемой является распознавание различных диалектов. Проанализированы наиболее распространенные системы распознавания акцентов и диалектов романо-германских языков. Выделены принципиальные различия между дикторами. Показано, что фонетические особенности несут в себе информацию, достаточную для различения диалектов. Обосновано, что наличие в языке большого количества диалектов, требует создания акустических моделей для каждого из них. Поставлен акцент на анализ и моделирование просодической структуры диалектов русского языка, при этом просодический подход основан на учении об ударении, занимающийся слогами с точки зрения их ударности и протяженности. Отмечено, что диалекты русского языка проявляют существенные отличия друг от друга с точки зрения особенностей их просодической структуры, включая различия в их ритмической структуре, темпе речи и длительности гласных звуков. Описано разработанное программное обеспечение для разметки звучащей речи, позволяющее пользователю взаимодействовать с речевой базой данных. Показан интерфейс разработанной системы. Визуализация аудиозаписи представляет собой осциллограмму. Выделены основные и второстепенные сущности, использованные в базе данных. Отмечено, каждая из сущностей хранит определенную информацию, касающуюся фонем и диктора. На основе разработанной системы распознавания диалектов русского языка предполагается создание речевого корпуса, который позволит получать информацию о произношениях фонем по различным заданным параметрам.

Ключевые слова: распознавание речи, диалект, звучащая речь, фонема, речевая база данных, диктор, дикторозависимость.
\end{abstract}

\section{ВВЕДЕНИЕ}

Автоматическое распознавание звуков речи - актуальная научная и техническая проблема, решение которой позволило бы значительно ослабить влияние негативных факторов ввода в ЭВМ звуковой текстовой информации и организовать управление с помощью звуков речи. Проблема ввода устной речи на сегодня решена на достаточно высоком уровне практического использова-

Бутенко Юлия Ивановна e-mail: iubutenko@bmstu.ru ния, однако имеет три принципиальных ограничения: ограничение персональное, так как автомат распознает язык только конкретного говорящего; ограничения относительно подготовки - автомат распознает язык только тогда, когда он заранее подготовлен; ограничение языковое - автомат распознает только ограниченное количество слов [1].

Следует отметить, что программные средства с такими ограничениями создают благоприятные условия для работы в автоматизированном управлении и информационном поиске, тем не менее, они непригодны для организации диалога с системой в массовом Commons Attribution 4.0 License. The content is available under Creative Commons Attribution 4.0 License. 
обслуживании на естественном языке. Для снятия этих ограничений нужно, чтобы автомат распознавал слова, отдельные звуки, реализованные любым говорящим. В настоящее время одной из главных технических проблем является организация эффективного восприятия компьютером так называемой сплошной речи. В сплошной речи сложно определить, где заканчивается одно слово и начинается другое. При этом акустические образы проговоренных слов намного больше зависят от контекста. В системах распознавания изолированных слов этих проблем нет, поскольку слова разделены паузами [2].

Артикуляторный аппарат человека производит звуки речи. Каждый звук имеет свои акустические характеристики, которые можно описать набором физических параметров. Осмысленность звуков в речевом потоке реализуется в форме мелодического непрерывного речевого фрагмента, в котором заложены необходимые семантические признаки [3].

Распознавание речи является междисциплинарной областью прикладной лингвистики, задачей которой является разработка моделей и методов, которые дают возможность распознавать и переводить устную речь в текст с помощью компьютеров. Она включает в себя знания и исследования из областей лингвистики, информатики и электротехники. Данная область является очень актуальной ввиду общего развития компьютерных технологий, увеличивающейся тенденции перехода к голосовым интерфейсам (например, голосовой ввод в переводчиках от Яндекс и Google, «умные колонки» от Amazon, Apple, Xiaomi и др.), а также возрастающей популярности нейронных сетей, которые используются во многих голосовых ассистентах (Siri от Apple [5], Cortana от Microsoft [5], а также Алиса от Яндекс[6]).

\section{1. АНАЛИЗ СУЩЕСТВУЮЩИХ СИСТЕМ РАСПОЗНАВАНИЯ ДИАЛЕКТОВ}

В настоящее время основной проблемой голосовых помощников зачастую является распознавание различных акцентов. В Великобритании, например, людям с региональ- ными диалектами трудно говорить с виртуальными ассистентами, такими как Siri и Alexa. Согласно исследованию, 79 \% людей с региональным акцентом намеренно изменяют свой голос, чтобы их понимали цифровые помощники [7]. Есть хорошо известное видео женщины с сильным шотландским акцентом, просящей Alexa сыграть песню, просьбы которой были неоднократно игнорированы.

Голосовые помощники выросли в популярности в последние годы, 2 из 5 взрослых ежедневно используют голосовой поиск [8]. Пользователи в других странах также изо всех сил пытаются поддерживать разговор с помощью голосовых технологий, что указывает на необходимость улучшения того, как голосовые устройства интерпретируют разные языки.

Программное обеспечение искусственного интеллекта обучается распознавать речь через звуковые образцы. Инженеры собирают сотни аудио-образцов, которые говорят о самых разных предметах [9]. Затем они записываются в аудиоклипы, и алгоритм учится распознавать паттерны между словами и звуком. Таким образом, исследователи должны будут ввести звуковые образцы, которые отклоняются от традиционных диалектов для улучшения голосовой технологии.

Несмотря на проблемы с распознаванием речи, голосовые помощники, такие как Siri, расширили спектр своей работы, включив туда другие акценты. Siri предлагает австралийский, британский, ирландский, южноафриканский и американский диалекты английского языка, в то время как GoogleAssistant запустил австралийский вариант английского языка в 2018 году. Alexa также распознает такие языки, как английский, немецкий, французский и японский.

В надежде спасти пользователей от дальнейшего смущения, компании задают своему искусственному интеллекту серию иногда довольно странных языковых упражнений. Например, внутри одной из лабораторий Amazon, голосовой помощник Alexа задается вопросом о том, насколько хорошо он слушает «говорящего, блуждающего робота на колесах» [10]. 
Ю. И. Бутенко, Ю. В. Строганов, В. И. Шевченко, Н. В. Славнов, А. В. Квасников

Большинство подходов требуют обучения голосовых помощников, в то время как диалекты должны быть идентифицированы по варианту языка. Важной составляющей для построения системы распознавания речи является словарь произношения.

Цель статьи - разработка программного обеспечения разметки звучащей речи для определения базовых характеристик диалектов русского языка.

\section{2. ОСОБЕННОСТИ РАЗЛИЧНЫХ ДИАЛЕКТОВ}

Следует отметить, что большинство независимых систем распознавания речи содержат набор акустических моделей (например, скрытые Марковские модели), параметры которых оцениваются при помощи речевых данных большого количества дикторов. В настоящее время выделяют два принципиальных различия, которые существуют между дикторами: акустические различия, которые связаны с размером и формой голосового тракта, и различия в произношении, которые обычно называют акцентом и часто обусловлены географически. Но, однако, на практике, довольно трудно получить полный охват всех региональных акцентов.

Как показывают наблюдения, системы распознавания речи работают не так хорошо, как дикторозависимые системы, в основном из-за необходимости моделирования вариаций дикторов в рамках одной модели.

Так как слова состоят из букв, учеными было проведено наблюдение за индивидуальным звучанием гласных, согласных, а также изучена каждая из этих структур [11]. В результате звуки были разделены на I и II фазы, при этом вторые фазы согласных равны друг другу, и разница между ними заключается только в первой фазе. Причиной изменения акцентов является временное удлинение второй фазы, в то время как первая фаза во время разговора остается прежней. Поэтому достаточно наблюдать за звучанием первой фазы распознавания речи [12], так как продление времени второй фазы не может изменить фонемный состав слова или предложения.
В связи с изложенным, в рамках исследования по диалектной идентификации предполагается разработка системы разметки звучащей речи для проведения более глубокого анализа эффективности известных фонотактических подходов на основе распознавания языков с целью идентификации диалектов русского языка.

Акцент ставится на анализ и моделирование просодической структуры диалектов русского языка. Просодический подход основан на учении об ударении, занимающимся слогами с точки зрения их ударности и протяженности. Диалекты русского языка проявляют существенные отличия друг от друга с точки зрения особенностей их просодической структуры, включая различия в их ритмической структуре, темпе речи и длительности гласных звуков. Возможно использовать данные просодические отличительные черты с целью автоматической идентификации диалекта говорящего со значительной точностью. Просодический подход моделирования также может значительно улучшить систему, которая использует фонотактические закономерности.

Базовой концепцией проводимого исследования является, что только фонетические особенности несут в себе информацию, достаточную для различения диалектов. Если в языке много диалектов, необходимо создавать акустическую модель для каждого из них. Дифференциация систем распознавания речи объективно отражает дифференциацию используемых человечеством языков. В результате неравномерного культурного и экономического развития используемые человечеством языки делятся на 2 группы: языки-доминанты, охватывающие все более и более широкие слои населения, и реликтовые языки, которыми пользуются исчезающие малочисленные этносы. Но исчезновение языков не проходит бесследно: их отдельные элементы включаются в лингвистические и фонетические конструкции частично включаются в состав языков-доминантов; также культурно-смысловой концепт не исчезает, а плавно перетекает в смысловой концепт языка-доминанта, и совместно с ранее погло- 
Система разметки звучащей речи для сравнительного анализа произношения в различных диалектах

щенными лингвистическими конструкциями провоцирует формирование новых диалектов. Прямым ответом на этот вызов является создание большего количества вариантов систем распознавания речи, но данные решения позволяют элиминировать краткосрочные проблемы, однако в долгосрочной перспективе требуется дальнейшее развитие в данной сфере искусственного интеллекта, позволяющего оперативно сформировать лингвистическую базу знаний диалекта и на ее основе сформировать возможности быстрого и точного перевода локальных языковых средств.

\section{3. СИСТЕМА РАЗМЕТКИ ЗВУЧАЩЕЙ РЕЧИ}

Разработанное программное обеспечение представляет собой веб-приложение, которое позволяет пользователю с помощью браузера взаимодействовать с речевой базой данных, размещенной на удаленном сервере. Для загрузки данных был разработан специальный интерфейс, позволяющий загружать аудиозапись в формате .wav и делать разметку фонем (рис. 1).

Этот интерфейс представляет собой виджет, который создает визуализацию загру-
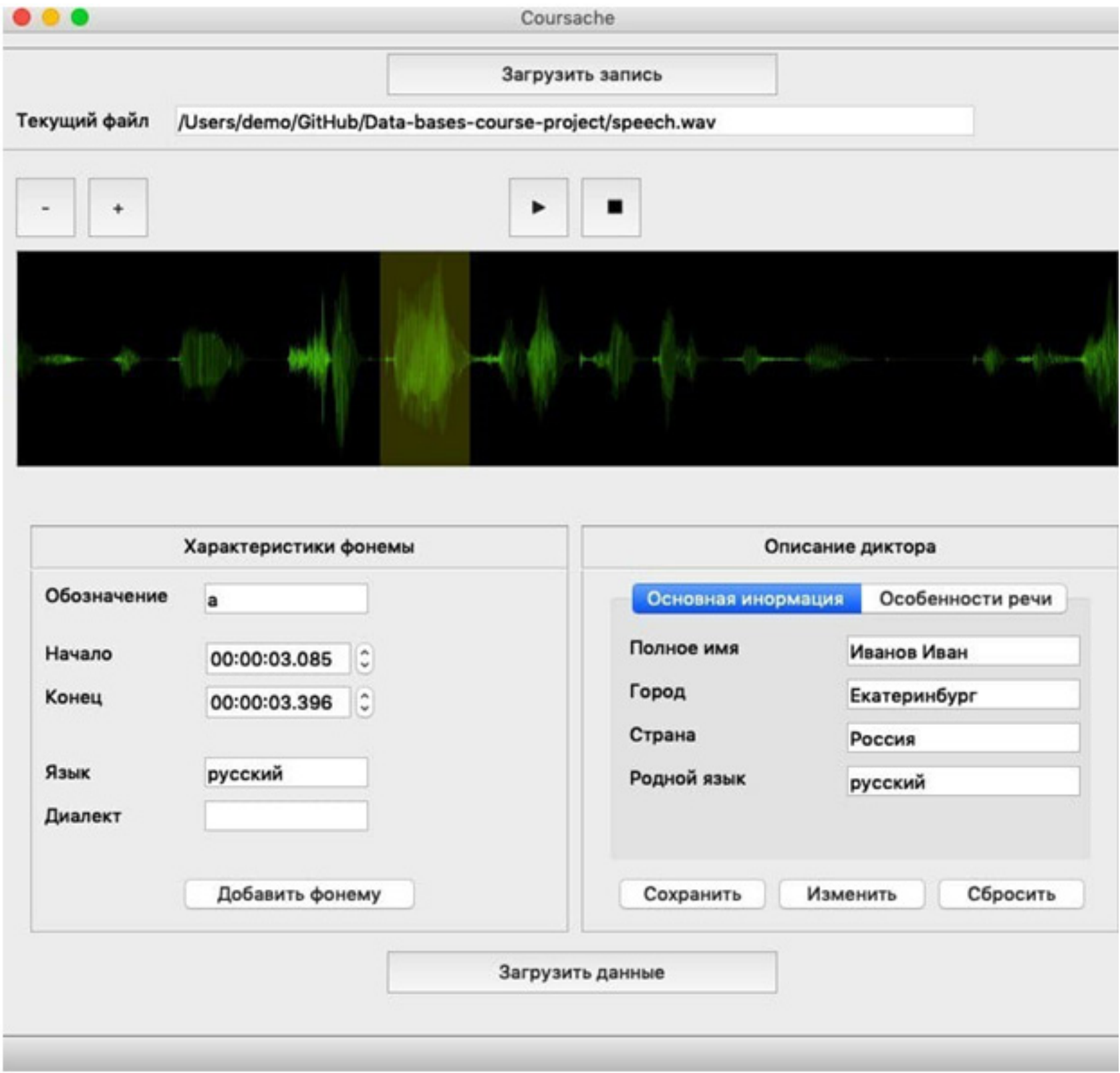

Рис. 1. Интерфейс системы разметки звучащей речи [Fig. 1. Speech markup system interface] 
Ю. И. Бутенко, Ю. В. Строганов, В. И. Шевченко, Н. В. Славнов, А. В. Квасников

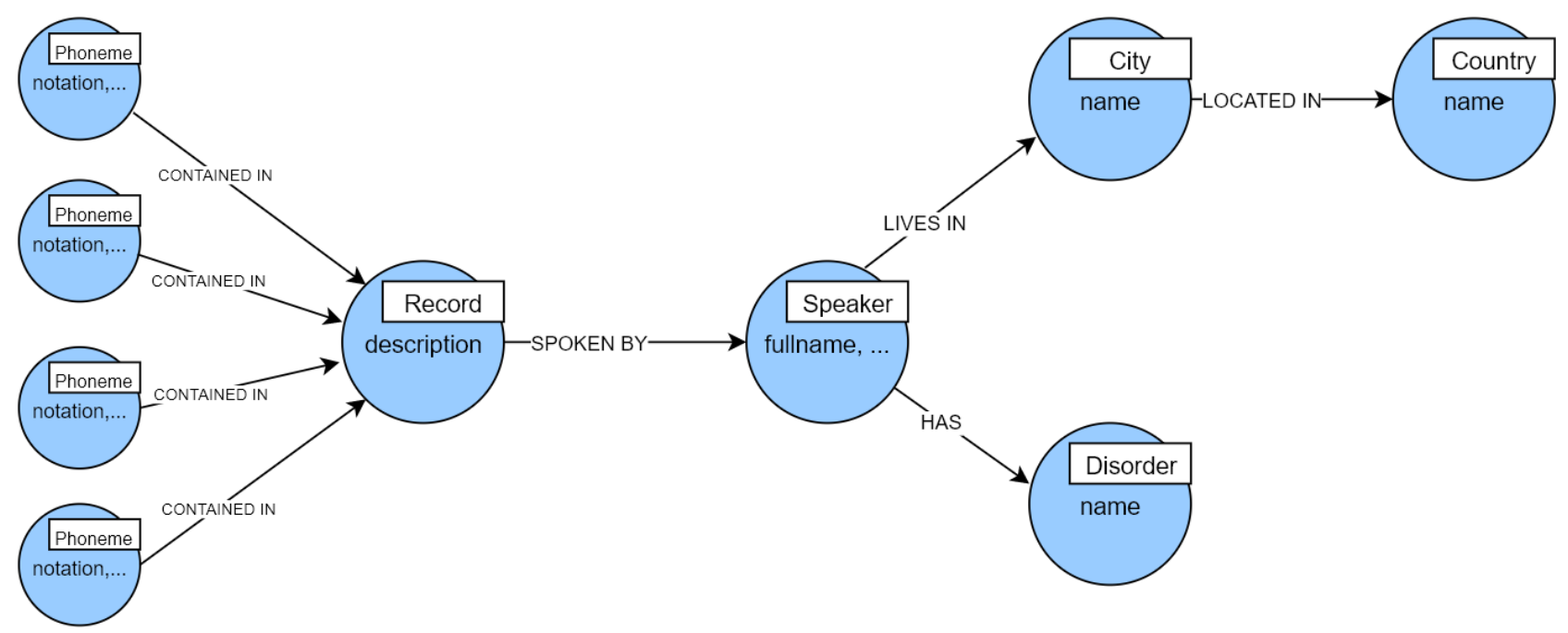

Рис. 2. Графовое представление модели

[Fig. 2 Graph representation of the model]

женной аудиозаписи, и набор форм для описания фонем и диктора. Визуализация аудиозаписи представляет собой осциллограмму, которую пользователь может масштабировать и перемещать с помощью полосы прокрутки. Также пользователь может выделять на осциллограмме необходимые участки, соответствующие определенным фонемам. После выделения некоторой фонемы, в специальную форму заносится информация о ее времени начала и завершения. Далее в данной форме пользователю необходимо указать язык, диалект и транскрипцию для данной фонемы. Однако, чтобы загрузить размеченные фонемы в базу данных, пользователю также необходимо заполнить форму с информацией о дикторе.

Для хранения фонем используется графовая база данных (рис. 2). Представление информации в виде графа открывает широкие возможности для описания связей между хранимыми данными. Еще одним преимуществом является то, что графовая база данных является достаточно гибким решением, так как позволяет расширять существующую структуру добавлением новых узлов или новых связей поверх существующих узлов.

Представление атрибутов 'город' и 'страна' отдельными узлами позволяет оптимально производить поиск по геоданным, т. е. такие запросы как «найти все бонемы, которые произнесли дикторьи, живущие в <город/странa>». Также атрибут 'ID записи' был преобразован в узел Record (запись) с атрибутом description (описание). Этот узел может содержать путь к файлу записи или какую-либо другую информацию. Поскольку у одного и того же диктора может быть несколько записей и все они могут отличаться друг от друга (например, были записаны в разный период жизни человека), добавление такого узла позволяет делать более вариативные запросы.

В данный момент основными сущностями, или узлами, в используемой базе данных являются 'фонема', 'диктор' и 'нарушение речи'. Второстепенными сущностями являются 'запись', 'страна' и 'город'. Каждая из сущностей хранит определенную информацию, касающуюся фонем и диктора. 'Фонема' содержит информацию о языке и диалекте, а также транскрипцию данной фонемы. 'Диктор' содержит полное имя и информацию о поле, возрасте и родном языке. 'Нарушение речи’ описывает наличие акцента или дефектов речи, если таковые имеются. Подобное разбиение позволяет получать информацию о произношениях фонем по различным заданным параметрам. Например, можно сделать выборку фонем русского языка, произнесенных людьми, которые имеют мужской пол, живут в Вологде, имеют акцент и чей родной язык является русским. 


\section{4. РЕЗУЛЬТАТЫ И ИХ ОБСУЖДЕНИЕ}

Разработанная система для разметки звучащей речи является основой для разработки речевого корпуса как совокупности речевых фрагментов, и созданных на их основе баз данных, которые обеспечены программными средствами доступа к ним [14-15]. Предполагается сбор голосовых записей двух видов: произнесение дикторами отдельных звуков, а также коротких текстов с частым употреблением исследуемых звуков в разных позициях - в начале и конце слова или слога, влияние соседних фонем и прочее. Предметом для дальнейшего исследования является определение минимальных единиц для сравнения (аллофон, фонема, сочетание нескольких фонем) диалектов, которые необходимо размечать в речевом корпусе. Более того, задача сбора аудиозаписей усложнена рядом факторов, таких как уровень образования диктора, длительным проживанием в другом регионе с ярко выраженным диалектом, наличием физиологических особенностей, развитием болезней, связанных с речью и дыханием.

\section{ЗАКЛЮЧЕНИЕ}

В настоящее время основной проблемой голосовых помощников является распознавание различных диалектов. Определено, что голосовые помощники расширили спектр своей работы, включив другие региональные диалекты для английского, немецкого, французского и других языков. Выделены два принципиальных различия между дикторами, проявляющиеся в акустических различиях и различиях в произношении. Обосновано, что фонетические особенности несут в себе информацию, достаточную для различения диалектов, а наличие в языке большого количества диалектов, требует создания акустических моделей для каждого из них. Разработано программное обеспечение для разметки звучащей речи, которое позволяет пользователю с помощью браузера взаимодействовать c речевой базой данных, размещенной на удаленном сервере. Показан интерфейс разработанной системы, представляющий со- бой виджет, который создает визуализацию загруженной аудиозаписи, и набор форм для описания фонем и диктора. Визуализация аудиозаписи представляет собой осциллограмму. Выделены основные сущности в используемой базе данных, которыми являются 'фонема', 'диктор' и 'нарушение речи', а второстепенные сущностями - 'запись', 'страна' и 'город'. Создание системы разметки звучащей речи для сравнительного анализа диалектов русского языка требует наличия определенного объема аудиозаписей дикторов. Предполагается, что для проведения сравнительного анализа диалектов дикторы будут произносить один и тот же текст, с целью последующего сравнения участков осциллограмм с одинаковыми последовательностями звуков. Сложности также представляют собой сами минимальные единицы, которые необходимо определять на осциллограмме. Предполагается дальнейшее создание речевого корпуса как совокупности речевых фрагментов, и созданных на их основе баз данных, которые обеспечены программными средствами доступа к ним.

\section{КОНФЛИКТ ИНТЕРЕСОВ}

Авторы декларируют отсутствие явных и потенциальных конфликтов интересов, связанных с публикацией настоящей статьи.

\section{СПИСОК ЛИТЕРАТУРЫ}

1. Волошин, В. Г. Компьютерная лингвистика / Г. В. Волошин. - Сумы: Университетская книга, 2004, - 382 с.

2. Бутенко, Ю. И. Методологические аспекты распознавания речи на основе многомерной статистической теории / Ю.И.Бутенко, И. В. Шостак // Нейрокомпьютеры: разработка, применение. - 2018. - № 2. C. 23-33.

3. Потапова Р. К. Речевая коммуникация: От звука к высказыванию / Р. К. Потапова, В. В. Потапов. - М. : Языки славянских культур, 2012. - $416 \mathrm{c}$.

4. An Exclusive Look at How AI and Machine Learning Work at Apple. - Режим доступа: 
https://www.wired.com/2016/08/an-exclusivelook-at-how-ai-and-machine-learning-work-atapple/ (дата обращения: 01.11.2019).

5. Let's talk Microsoft, neural networks and natural language processing for AI. - Режим доступа: https://www.windowscent-ral.com/ neural-networks-and-natural-language-processing-what-are-they-and-microsoft (дата обращения: 25.10.2019).

6. Как «Яндекс» создавал «Алису». - Режим доступа: https://vc.ru/future/26878-yaalice (дата обращения: 01.11.2019).

7. Research Highlights Fears Technology Could Eradicate Regional Accents. - Режим доступа: https://www.life.org.uk/news/technologycould-eradicate-regional-accents (дата обращения: 15.10.2019).

8. Voice Search Statistics to Prepare You for the Voice Search Revolution. - Режим доступа: https://www.wordstream.com/blog/-ws/2018/ 04/10/voice-search-statistics-2018 (дата обращения: 15.10.2019).

9. Как это работает? Распознавание речи. - Режим доступа: https://yandex.ru/blog/ co-mpany/72171 (дата обращения: 20.10.2019).

10. The accent gap // The Washington Post. Режим доступа: https://www.washing-tonpost. com/graphics/2018/business/alexa-does-notunderstand-your-accent/ (дата обращения: 17.10.2019).

11. Kardava, I. Solving the problem of the accents for speech recognition systems / I. Kardava, J. Antidze, N. Gulua // International Journal of Signal Processing Systems. - 2016. № 4(3). - P. 235-238.

12. Juan, $H$. Conversational Language Processing: A Guide to Theory, Algorithm, and System Development // H. Juan, A. Acero, H. U. Hong. - New Jersey: PrenticeHall PTR, 2001. - $960 \mathrm{p}$.

13. Фролов, А. В. Синтез и распознавание речи. Современные решения / Г. В. Фролов. М. : Связь, - 2003. - 216 с.

14. Израилова, Э. С. О создании фонетико-акустической базы в рамках синтеза чеченской речи / Э. С. Израилова // Вестник ВГУ, серия: Системный анализ и информационные технологии. - 2017. - № 2. - С. 111-115.

15. Полицын, С. А. Применение комплекса инструментов управления корпусами текстов при решении задач компьютерной лингвистики / С. А. Полицын, Е. В. Полицына // Вестник ВГУ, серия: Системный анализ и информационные технологии, - 2019. - № 2. - С. 134-142.

Бутенко Юлия Ивановна - канд. тех. наук, доцент кафедры «Романо-германские языки», Московский государственный технический университет им. Н. Э. Баумана.

E-mail: iubutenko@bmstu.ru

https://orcid.org/0000-0002-9776-5709

Строганов Юрий Владимирович - старший преподаватель кафедры «Программное обеспечение ЭВМ и информационные технологии», Московский государственный технический университет им. Н. Э. Баумана. E-mail: stroganovyv@bmstu.ru

https://orcid.org/0000-0001-5628-7395

Шевченко Валерия Игоревна - магистрант факультета «Лингвистика», Московский государственный технический университет им. Н. Э. Баумана.

E-mail: leeer6@yandex.ru

https://orcid.org/0000-0001-5863-5621

Славнов Николай Вадимович - магистрант факультета «Информатика и управление», Московский государственный технический университет им. Н. Э. Баумана,

E-mail:nv.slavnov@gmail.com

https://orcid.org/0000-0002-8179-154X

Квасников Александр Владимирович - магистрант факультета «Информатика и управление», Московский государственный технический университет им. Н. Э. Баумана.

E-mail: videot4pe@gmail.com

https://orcid.org/0000-0001-7014-0111 


\title{
SPEECH ANNOTATION SYSTEM FOR THE COMPARATIVE ANALYSIS OF PRONUNCIATION IN DIFFERENT DIALECTS
}

\author{
(c) 2020 Iu. I. Butenko ${ }^{\bowtie}$, Iu. V. Stroganov, V. I. Shevchenko, N. V. Slavnov, A. V. Kvasnikov \\ Bauman Moscow State Technical University \\ 5/1, 2nd Baumanskaya Str., 105005 Moscow, Russian Federation
}

\begin{abstract}
The article describes the development of an annotation system for the comparative analysis of pronunciation in different dialects of the Russian language. It emphasizes that voice input is nowadays widely used. The main challenge still facing voice assistants is the need to recognise different dialects. The most popular systems for the recognition of accents and dialects of Romance and Germanic languages were analysed. The key differences between speakers were determined. The article shows that phonetic features are informative enough to be used for distinguishing dialects. It also demonstrates that a large number of dialects in the Russian language requires the creation of an acoustic model for each of them. The article focuses on the analysis and modelling of the prosodic structure of the Russian dialects. The prosodic approach is based on the stress theory, which considers syllables from the point of view of emphasis and duration. It is noted that the dialects of the Russian language differ significantly in terms of their prosodic structure, i.e. their rhythmic structure, the tempo of speech, and the length of vowels. Software was developed for speech annotation which allows the user to interact with the speech database. The interface of the developed system is demonstrated. Audio recordings are visualized by oscillograms. The primary and secondary entities used in the database are highlighted. Each entity stores certain information regarding the phonemes and the speaker. The developed system for the recognition of dialects of the Russian language can be used to create a speech corpus, which will allow obtaining information about the pronunciation of phonemes using specific parameters.

Keywords: speech recognition, dialect, speech, phoneme, speech corpus, speaker, voice dependence.
\end{abstract}

\section{CONFLICT OF INTEREST}

The authors declare the absence of obvious and potential conflicts of interest related to the publication of this article.

\section{REFERENCES}

1. Voloshin V. G. Computer Linguistics. Sumy. University Book. 2004. 382 p.

2. Butenko Iu. I, Shostak I. V. Methodological Aspects of Speech Recognition on the basis of the Multidimensional Statistical Theory. Neurocomputers: Development, Application. 2018. №2. P. 23-33.

Butenko Iuliia I.

e-mail: iubutenko@bmstu.ru
3. Potapova R. K., Potapov V. V. Speech Communication: from Sound to Statement. Moscow: Languages of Slavic cultures. 2012. 416 p.

4. An Exclusive Look at How AI and Machine Learning Work at Apple. - Pre-step mode: Available at https://www.wired.com /2016/08/anexclusive-look-at-how-ai-and-machine-learning -work-at-apple/. (date of access: 01.11.2019).

5. Let's Talk Microsoft, Neural Networks and Natural Language Processing for AI. Available at: https://www.windowscentral.com/neural-networks-and-natural-language-rocessingwhat-are-they-and-microsoft (date of access: 25.10.2019).

6. How "Yandex" Created "Alice". - Available at: https://vc.ru/future/26878-ya-alice (date of access: 01.11.2019). 
7. Research Fears Technology Could Eradicate Regional Accents. - Available at: https:// www.life.org.uk/news/technology-could-eradicate-regional-accents (date of access: 15.10.2019).

8. Voice Search Statistics to Prepare You for the Voice Search Revolution. - Available at: https:// www.wordstream.com/blog/ws/2018/04/10/ voice-search-statistics-2018 (date of access: 15.10.2019).

9. How does it work? Speech Recognition. Available at: https://yandex.ru/blog/com-pany/72171 (date of access: 20.10.2019).

10. The Accent Gap // The Washington Post. Available at: https://www.washing-tonpost.com/ graphics/2018/business/alexa-does-not-understand-your-accent/ (date of access: 17.10.2019).

11. Kardava I., Antidze J., Gulua N. Solving the Problem of the Accents for Speech Recognition Systems. International Journal of Signal
Processing Systems. 2016. 4(3). P. 235-238. doi: 10.18178/ijsps.4.3.235-238

12. Huang X., Acero A., Hon H. W., Foreword By-Reddy, R. Spoken Language Processing: A Guide to Theory, Algorithm, and System Development. New Jersey. PrenticeHall PTR. 2001. $960 \mathrm{p}$.

13. Frolov A. V. Synthesis and Speech Recognition. Up-to-date Solutions. Moscow. Svyaz. 2003. $216 \mathrm{p}$.

14. Izrailova E. S. On Creating Phonetic-acoustic Base for Chechen Speech Synthesis. Vestnik VSU, series: System analysis and information technologies. 2017. 2. P. 111-115.

15. Politsyn S. A., Politsyna E. V. Application of the Text Body Control Tools Complex for the Computer Linguistics Problems Solution (in Russian). Vestnik VSU, series: System analysis and information technologies. 2019. No 2. P. 134-142.

Butenko Iuliia I. - PhD in Technical Sciences, Associate Professor, Department of Romance and Germanic Languages, Bauman Moscow State Technical University.

E-mail: iubutenko@bmstu.ru

https://orcid.org/0000-0002-9776-5709

Stroganov Iurii V. - senior lecturer, department of Computer software and information technology, Bauman Moscow State Technical University.

E-mail: stroganovyv@bmstu.ru

https://orcid.org/0000-0001-5628-7395

Shevchenko Valeriia I. - Senior lecturer, Department of Computer Software and Information Technologies, Bauman Moscow State Technical University.

E-mail: leeer6@yandex.ru

https://orcid.org/0000-0001-5863-5621

Slavnov Nikolai V. - MSc student, Faculty of Linguistics, Bauman Moscow State Technical University. E-mail: nv.slavnov@gmail.com

https://orcid.org/0000-0002-8179-154X

Kvasnikov Alexander V. - MSc student, Faculty of Computer Science and Control Systems, Bauman Moscow State Technical University.

E-mail: videot4pe@gmail.com

https://orcid.org/0000-0001-7014-0111 